\title{
Possible Involvement of Human Mast Cells in the Establishment of Pregnancy via Killer Cell Ig-Like Receptor 2DL4
}

\author{
Chiyuki Ueshima, * Tatsuki R. Kataoka, * Masahiro Hirata, * Akihiko Sugimoto, * Yoshiki Iemura, * Sachiko Minamiguchi, \\ Takashi Nomura, ${ }^{\dagger}$ and Hironori Haga*
}

From the Departments of Diagnostic Pathology* and Dermatology, ${ }^{\dagger}$ Kyoto University Hospital, Kyoto, Japan

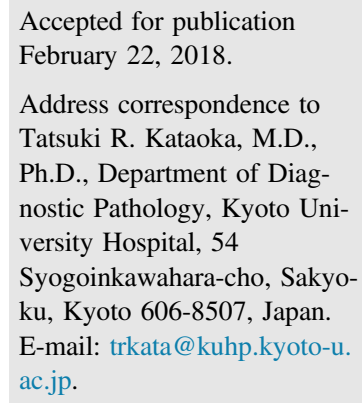

\begin{abstract}
The involvement of mast cells in the establishment of pregnancy is unclear. Herein, we found that human mast cells are present in the decidual tissues of parous women and expressed a human-specific protein killer cell Ig-like receptor (KIR) 2DL4, a receptor for human leukocyte antigen G expressed on human trophoblasts. In contrast, decreased numbers of decidual mast cells and reduced KIR2DL4 expression were observed in these cells of infertile women who had undergone long-term corticosteroid treatment. Co-culture of the human mast cell line, LAD2, and human trophoblast cell line, HTR-8/SVneo, accelerated the migration and tube formation of HTR-8/SVneo cells in a KIR2DL4-dependent manner. These observations suggest the possible involvement of human mast cells in the establishment of pregnancy via KIR2DL4 and that long-term corticosteroid treatment may cause infertility by influencing the phenotypes of decidual mast cells. (Am J Pathol 2018, 188: 1497-1508; https://doi.org/10.1016/ j.ajpath.2018.02.012)
\end{abstract}

The presence of immunocompetent cells in decidual tissue is essential for the establishment of pregnancy. ${ }^{1,2}$ Decidual natural killer (NK) cells and decidual dendritic cells are involved in angiogenesis in decidual tissues. ${ }^{1}$ Regulatory $\mathrm{T}$ cells (Tregs) are essential for implantation. ${ }^{2}$ Mast cells, another type of immunocompetent cells, ${ }^{3}$ are present in mouse and human decidual tissue. ${ }^{4}$ Studies using mast cell-deficient $K I T^{W-s h / W-s h}$ mice revealed that mast cells are dispensable for, ${ }^{5}$ but enhance, the establishment of pregnancy. ${ }^{6}$ The number of murine mast cells was increased by transfer of Tregs into the decidual tissue, ${ }^{7}$ and mast cell chymase was thought to be necessary for decidual vascular remodeling in mice and humans. ${ }^{8}$ However, the roles of decidual mast cells have not been determined in detail, especially in humans.

Human mast cells express killer cell Ig-like receptor 2DL4 (KIR2DL4/CD158d), ${ }^{9}$ a member of the KIRs. ${ }^{10}$ KIRs are human-specific transmembrane proteins, which are categorized by the presence or absence of the immunoreceptor tyrosine-based inhibitory motif in the cytoplasmic domain. ${ }^{10}$ KIR2DL4 contains the immunoreceptor tyrosine-based inhibitory motif, which can transduce inhibitory signals to human NK cells. ${ }^{11}$ The ligand of KIR2DL4 was identified as human leukocyte antigen (HLA)-G, the expression of which is observed in human trophoblasts under physiological conditions. $^{12,13}$ Therefore, KIR2DL4 is thought to suppress the cytotoxic activity of human decidual NK cells against the embryo when interacting with HLA-G derived from trophoblasts at the fetal-maternal interface. ${ }^{14}$ To our knowledge, the role of KIR2DL4 on human decidual mast cells in the establishment of pregnancy has not been reported.

Herein, we hypothesized that KIR2DL4 of human decidual mast cells plays roles in the establishment of pregnancy.

Supported by a FUSO Pharmaceutical Industries, LTD. (Japan) gran (T.R.K.) and JSPS KAKENHI grants 15K08362 (T.R.K.) and 16K19080 (C.U.).

C.U. and T.R.K. contributed equally to this work.

Disclosures: None declared. 


\section{Materials and Methods}

\section{Patients}

Decidual samples collected at the Kyoto University Hospital (Kyoto, Japan) from 2006 to 2016 were obtained. Thirteen patients who underwent long-term corticosteroid therapy for autoimmune diseases or after liver or kidney transplantation and who were diagnosed as infertile, according to World Health Organization criteria, were included; three patients were excluded from the evaluation because their samples did not include decidual tissues (Table 1). Ten age-matched patients who had given birth to multiple children and 10 other patients diagnosed as infertile because of unknown causes (but who had not undergone corticosteroid therapy) from 2006 to 2016 were selected as normal controls (Table 1). All cases were spontaneously aborted. A total of 6 of 30 decidual tissues were discharged, and 24 of 30 decidual tissues were collected by curettage (Table 1).
These patients signed the Kyoto University Hospital Informed Consent Form for the Non-therapeutic Use of Histopathological Materials, and the signed forms were uploaded into each electronic health record.

\section{Cells}

LAD2 cells (kindly provided by Arnold S. Kirshenbaum, Laboratory of Allergic Diseases, National Institute of Allergy and Infectious Diseases, NIH, Bethesda, MD), used as a human mast cell model, were cultured in StemPro-34 containing recombinant human stem cell factor (SCF; Peprotech, Rocky Hill, NJ). ${ }^{15}$ HTR-8/SVneo cells (kindly provided by Dr. Charles H. Graham, Department of Biomedical and Molecular Sciences, Queen's University, Kingston, ON, Canada) were cultured in RPMI 1640 medium supplemented with $10 \%$ fetal calf serum (FCS). ${ }^{16}$

Table 1 Clinical Parameters of Study Subjects

\begin{tabular}{|c|c|c|c|c|c|c|}
\hline Case no. & Fertility & Age, years & TPAL* & Sampling & Clinical diagnosis & Corticosteroid \\
\hline 1 & Parous & 22 & $3 G 2 P$ & Delivery & Incomplete abortion & None \\
\hline 2 & Parous & 37 & $2 \mathrm{G} 2 \mathrm{P}$ & Delivery & Incomplete abortion & None \\
\hline 3 & Parous & 37 & $3 G 3 P$ & Curettage & Missed abortion & None \\
\hline 4 & Parous & 31 & $2 \mathrm{G} 2 \mathrm{P}$ & Curettage & Incomplete abortion & None \\
\hline 5 & Parous & 31 & $5 G 2 P$ & Curettage & Incomplete abortion & None \\
\hline 6 & Parous & 33 & $2 \mathrm{G} 2 \mathrm{P}$ & Curettage & Missed abortion & None \\
\hline 9 & Parous & 36 & $6 \mathrm{G} 2 \mathrm{P}$ & Curettage & Missed abortion & None \\
\hline 10 & Parous & 43 & $2 \mathrm{G} 2 \mathrm{P}$ & Curettage & Missed abortion & None \\
\hline 11 & Infertile & 40 & OGOP & Curettage & Missed abortion & None \\
\hline 12 & Infertile & 40 & OGOP & Curettage & Missed abortion & None \\
\hline 13 & Infertile & 41 & OGOP & Delivery & Incomplete abortion & None \\
\hline 14 & Infertile & 29 & OGOP & Curettage & Missed abortion & None \\
\hline 18 & Infertile & 32 & OGOP & Curettage & Missed abortion & None \\
\hline 19 & Infertile & 33 & OGOP & Curettage & Missed abortion & None \\
\hline 20 & Infertile & 23 & OGOP & Delivery & Incomplete abortion & None \\
\hline 21 & Infertile & 42 & $1 G 0 P$ & Curettage & Missed abortion & $\begin{array}{l}\text { 5-15 mg/day ( } 20 \text { to } 33 \text { years old), } \\
25 \mathrm{mg} / \text { day ( } 34 \text { to } 39 \text { years old), } \\
\text { none ( } 40 \text { years old to present) for SLE }\end{array}$ \\
\hline 22 & Infertile & 27 & $1 G 0 P$ & Curettage & Missed abortion & $\begin{array}{l}\text { 15-20 mg/day after liver } \\
\text { transplantation ( } 8 \text { years old to present) }\end{array}$ \\
\hline 23 & Infertile & 30 & OGOP & Delivery & Incomplete abortion & $5 \mathrm{mg} /$ day from 18 years old for SLE \\
\hline 24 & Infertile & 35 & OGOP & Curettage & Missed abortion & $9 \mathrm{mg} /$ day from 24 years old for SLE \\
\hline 25 & Infertile & 27 & $1 \mathrm{GOP}$ & Curettage & Missed abortion & $7.5-20 \mathrm{mg} /$ day from 18 years old for SLE \\
\hline
\end{tabular}

*TPAL shows gravidity and parity, except for pregnancy status before the current samples have been collected.

MCTD, mixed connective tissue disease; MS, multiple sclerosis; SLE, systemic lupus erythematosus; TPAL, term births/premature births/abortions/living children. 


\section{Antibodies and Reagents}

Anti-KIR2DL4 agonistic antibody (mouse monoclonal IgG, clone 181703) was purchased from R\&D Systems (Minneapolis, MN). Anti-KIR2DL4 antibody (rabbit polyclonal IgG, 2643R), used for immunohistochemistry, immunocytochemistry, and immunoblotting, was purchased from Bioss (Woburn, MA). Anti-mast cell tryptase (MCT) antibody (mouse monoclonal IgG, clone AA1), anti-FOXP3 antibody (mouse monoclonal IgG, clone 236A/E7), and anti-glyceraldehyde 3-phosphate dehydrogenase antibody (mouse monoclonal $\mathrm{IgG}$, clone 6C5) were obtained from Abcam (Cambridge, MA). Anti-CD3 antibody (rabbit monoclonal IgG, clone 2GV6) was purchased from Roche Diagnostics (Mannheim, Germany). Anti-human leukemia inhibitory factor (LIF) antibody (goat polyclonal IgG, P15018) for neutralization assay was purchased from R\&D Systems. Anti-phosphorylated STAT3 (Tyr705) antibody (rabbit monoclonal IgG, clone D3A7) was purchased from Cell Signaling Technology (Beverly, MA). Anti-HLA-G antibody (mouse monoclonal IgG, clone $87 \mathrm{G}$ ) for blocking the interaction between KIR2DL4 and HLA-G was purchased from Exbio Praha (Praha, Czech Republic). Goat F(ab')2 anti-mouse IgG-H\&L (AP) preadsorbed (ab98724), goat anti-mouse IgG H\&L (Alexa Fluor 488; ab150113), and goat anti-rabbit IgG H\&L (Alexa Fluor 594) preadsorbed (ab150084) were purchased from Abcam. The secondary antibodies for Western blotting and peroxidaselabeled anti-rabbit or anti-mouse IgG antibodies were purchased from Santa Cruz Biotechnology (Dallas, TX). The fluoroshield mounting medium with DAPI was purchased from Abcam. The corticosteroid dexamethasone was purchased from Sigma-Aldrich (D4902; St. Louis, MO). We used dexamethasone at $1 \mu \mathrm{mol} / \mathrm{L}$ in $100 \%$ ethanol. ${ }^{17}$ KIR2DL4-targeting shRNA lentiviral particles and offtarget control particles were purchased from Santa Cruz Biotechnology. Infection and subsequent selection of these viral particles were performed according to the manufacturer's instructions. The matrix metalloproteinase (MMP) inhibitor GM6001 was purchased from Calbiochem (Merck Millipore, Darmstadt, Germany) and was used at a concentration of $0.5 \mathrm{nmol} / \mathrm{L}$ in dimethyl sulfoxide.

\section{Immunohistochemistry}

To count the numbers of mast cells and Treg cells in the decidual tissues, tissue sections were deparaffinized with xylene, rehydrated, and pretreated with $0.3 \%$ hydrogen peroxide for 5 minutes, followed by blocking of background staining using Protein Block (X0909; DakoCytomation, Glostrup, Denmark). To detect decidual mast cells, antiMCT antibody was added after steam heating for 30 minutes, and the sections were incubated for 90 minutes at room temperature. Staining was performed using an ENVISION kit (DakoCytomation), according to the manufacturer's instructions. To detect Treg cells, anti-FOXP3 antibody was added after steam heating for 30 minutes, and the sections were incubated for 1 hour at room temperature. Goat F(ab')2 anti-mouse IgG-H\&L (AP) preadsorbed was added, and the sections were incubated for 30 minutes at room temperature. Staining was performed using the Vector Blue Alkaline Phosphatase Substrate Kit III (SK-5300; Vector Laboratories, Burlingame, CA), according to the manufacturer's instructions. Anti-CD3 antibody was added, and the sections were incubated for 1 hour at room temperature. Staining was performed using Histofine Simple Stain MAX-PO (R) (Nichirei, Tokyo, Japan), according to the manufacturer's instructions. Stained sections were imaged under a BX45 microscope (Olympus, Tokyo, Japan) equipped with a DP26 digital camera (Olympus). Three fields $(\times 200)$ showing the largest, second largest, and third largest numbers of MCT-positive or CD3- and FOXP3positive cells in the decidual tissue were selected, and the total cell numbers in each sample were counted.

For double immunofluorescence staining, the tissue sections were deparaffinized with xylene, rehydrated, and pretreated with $0.3 \%$ hydrogen peroxide for 5 minutes; they were then steam heated for 30 minutes. Anti-KIR2DL4 antibody (rabbit polyclonal IgG) or control rabbit IgG was added for 90 minutes at room temperature, followed by goat anti-rabbit IgG H\&L (Alexa Fluor 594). Anti-MCT antibody or control mouse IgG was added for 30 minutes at room temperature, followed by goat anti-mouse $\mathrm{IgG} \mathrm{H} \& \mathrm{~L}$ (Alexa Fluor 488). The slides were mounted with fluoroshield mounting medium with DAPI. Sections were imaged with a BX63 microscope (Olympus) equipped with an ORCA Flash 2.8 digital camera (Hamamatsu Photonics, Shizuoka, Japan).

\section{Immunoblotting}

LAD2 cells were collected after overnight incubation with ethanol or $1 \mu \mathrm{mol} / \mathrm{L}$ corticosteroid, and cell lysates were prepared. Proteins were separated by gel electrophoresis, and target peptides were detected, as previously described. ${ }^{18}$ The immunoblots were scanned using Light-Capture II (ATTO, Tokyo, Japan), and the intensity of protein bands was analyzed using the CS Analyzer (ATTO).

\section{ELISA for Mast Cell Tryptase}

LAD2 cells were collected after overnight incubation with ethanol or $1 \mu \mathrm{mol} / \mathrm{L}$ corticosteroid. Cell lysates were prepared, and MCT was detected using the Human MCT Enzyme-Linked Immunosorbent Assay (ELISA) Kit (CSBE09012h; Cusabio Biotech Co, Ltd, Wuhan, China), according to the manufacturer's protocol.

\section{Immunocytochemistry}

To confirm KIR2DL4 knockdown, immunocytochemistry was performed. Mock or KIR2DL4 knockdown LAD2 
A
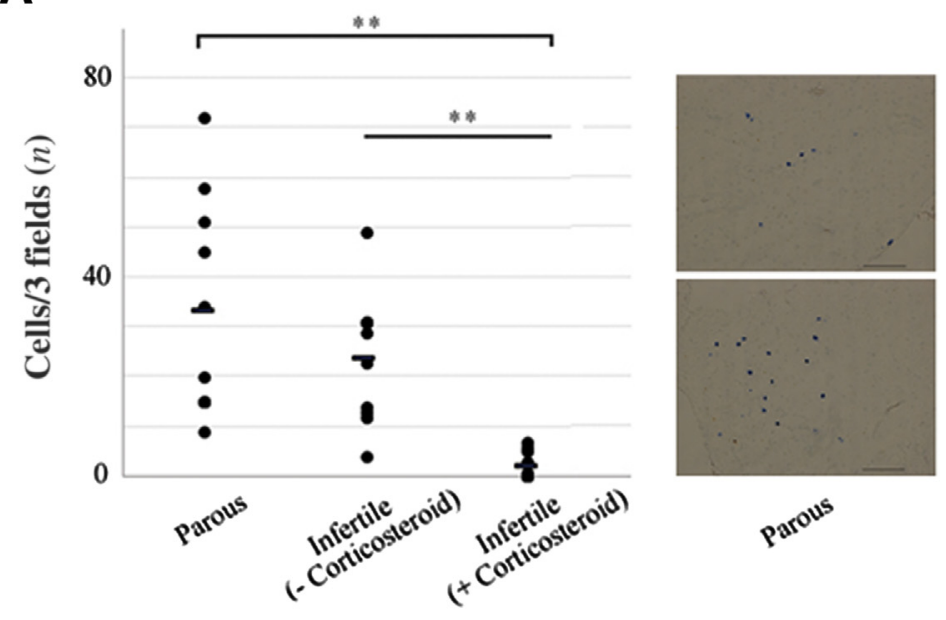

\section{MCT (Blue)}

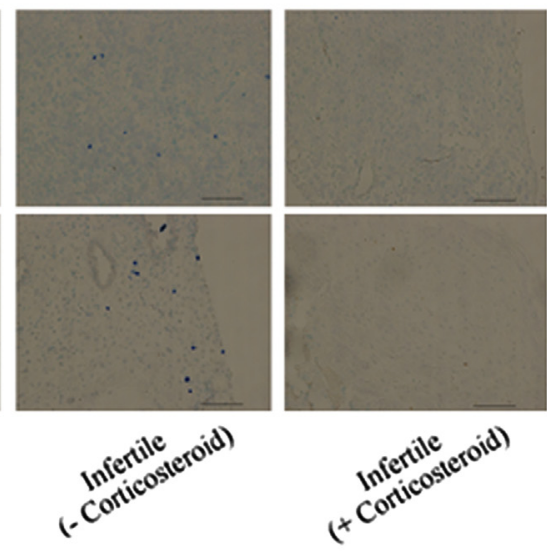

B

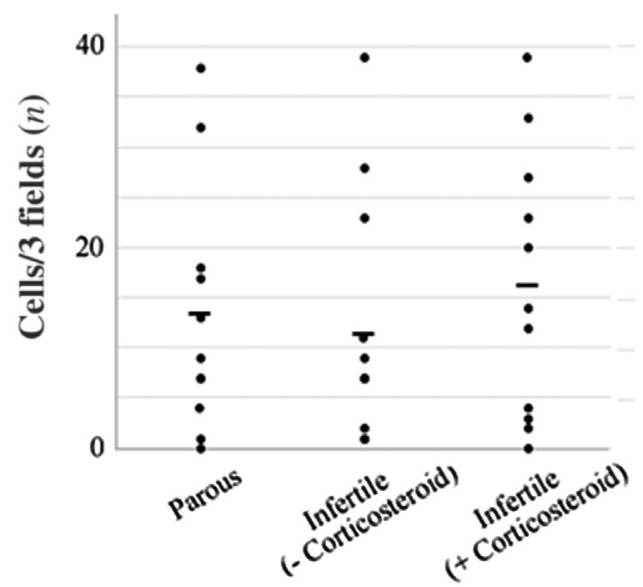

CD3 (Brown) / FOXP3 (Blue)
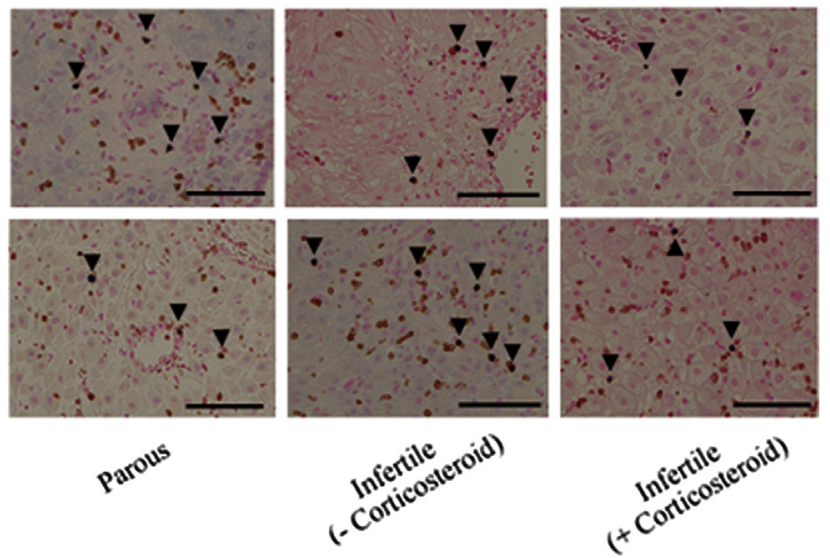

Figure 1 The number of decidual mast cells decreases in infertile women undergoing long-term corticosteroid treatment. A: Comparison of numbers of decidual mast cells in parous women, women without corticosteroid treatment, and infertile women undergoing long-term corticosteroid treatment. Representative distribution of mast cell tryptase (MCT)-positive decidual mast cells of each group is shown. B: Comparison of decidual regulatory T cell (Treg) number among parous women, women without corticosteroid treatment, and infertile women who had undergone long-term corticosteroid treatment. Representative distribution of CD3-/FOXP3-positive decidual Tregs (arrowheads) of each group is shown. ${ }^{*} P<0.01$. Scale bars $=100 \mu \mathrm{m}(\mathbf{A}$ and $\mathbf{B})$.

cells were collected and centrifuged at $8 \times g$ for 3 minutes, and the cell pellets were resuspended in $20 \%(\mathrm{v} / \mathrm{v})$ buffered formalin ( $\mathrm{pH}$ 7.0), followed by centrifugation at $24 \times g$ for 5 minutes. The cell pellets were dehydrated and embedded in paraffin, after which the paraffin blocks were cut into sections ( 3 to $4 \mu \mathrm{m}$ thick). The tissue sections were deparaffinized with xylene, rehydrated, and pretreated with $0.3 \%$ hydrogen peroxide for 5 minutes. Anti-KIR2DL4 antibody (rabbit polyclonal) was added, and incubation continued for 2 hours at room temperature. Staining was performed using an ENVISION kit (DakoCytomation), according to the manufacturer's instructions.

To evaluate STAT3 status in HTR-8/SVneo cells, aliquots of $2 \times 10^{5} \mathrm{LAD} 2$ cells in $200 \mu \mathrm{L}$ medium per well were cultured for 8 hours in two-well chamber slides containing confluent HTR-8/SVneo cells, with or without control IgG or anti-human LIF antibody $(10 \mu \mathrm{g} / \mathrm{mL})$. After three washes with phosphate-buffered saline, the adherent HTR-8/SVneo cells were fixed with $100 \%$ ethanol for 1 hour at $4^{\circ} \mathrm{C}$. After three washes with phosphate-buffered saline, cells were incubated with anti-phosphorylated STAT3 (Tyr705) antibody for 1 hour at $4^{\circ} \mathrm{C}$. Staining was performed using an ENVISION kit (DakoCytomation), according to the manufacturer's instructions. The slides were imaged using the BX45 microscope (Olympus) equipped with a DP26 digital camera (Olympus).

\section{Migration Assessment}

Migration of HTR-8/SVneo cells toward LAD2 cells was assessed using Matrigel-coated Transwell polycarbonate membranes $(8-\mu \mathrm{m}$ pores; BD Biosciences, Franklin Lakes, NJ). Aliquots of $400 \mu \mathrm{L}$ StemPro-34 only, StemPro-34 
A

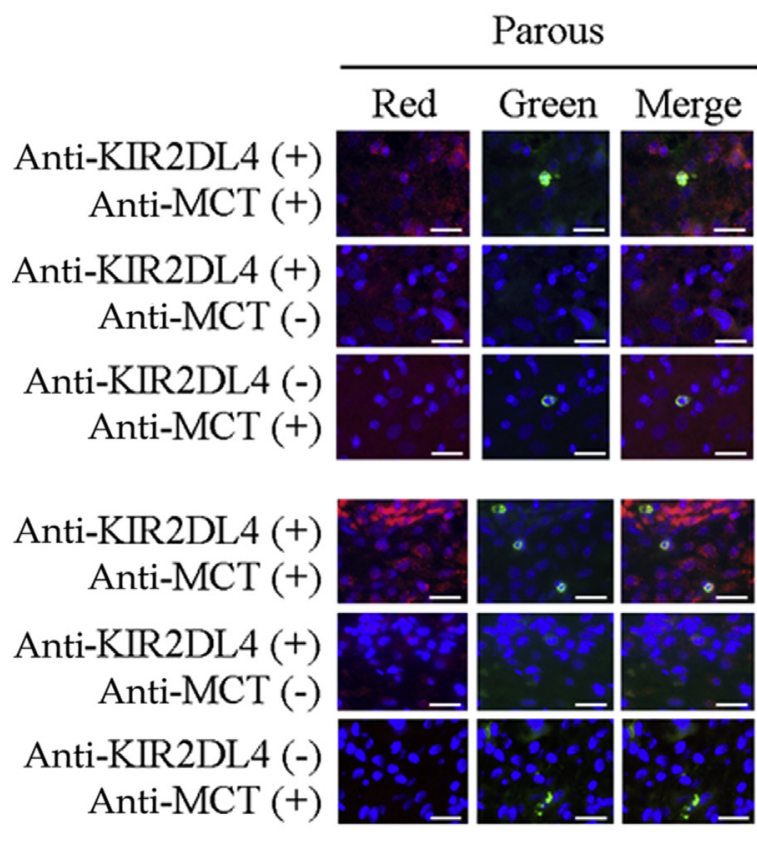

B

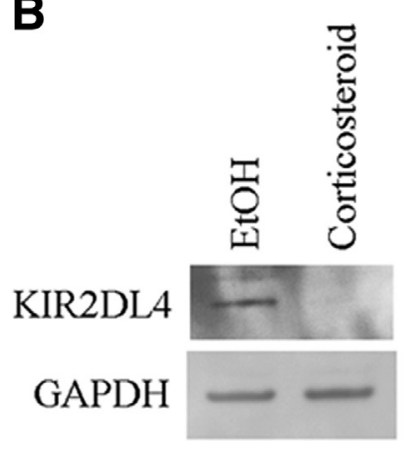

Infertile
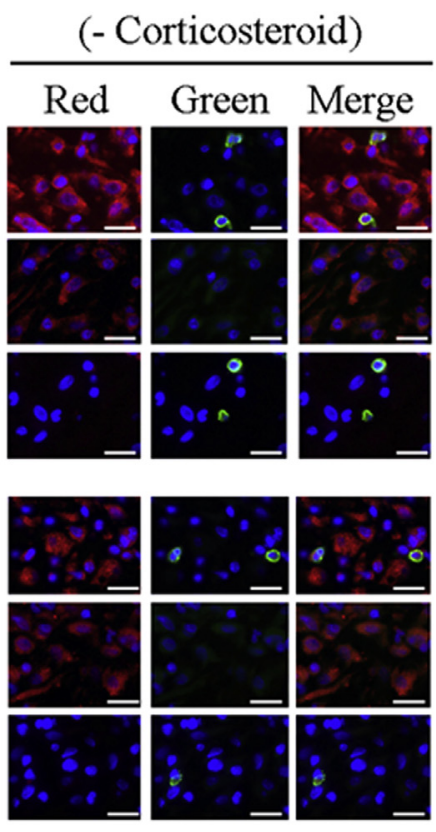

Infertile
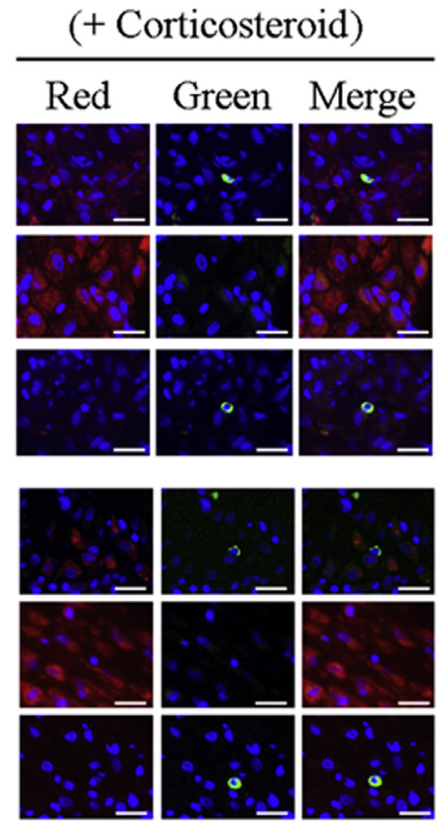

Figure 2 Decidual mast cells express KIR2DL4 protein in parous women and women without corticosteroid treatment but not in the infertile women who had undergone long-term corticosteroid treatment, and the protein expression of KIR2DL4 and mast cell tryptase (MCT) in a human mast cell line of LAD2 cells is suppressed by corticosteroid treatment. A: Expression of KIR2DL4 in MCT-positive decidual mast cells in parous women, women without corticosteroid treatment, and infertile women who had undergone long-term corticosteroid treatment. Two representative images of each group are shown. Immunohistochemistry was used to detect the expression of KIR2DL4 protein (red) and MCT protein (green). B: Expression of KIR2DL4 protein in LAD2 cells. Representative immunoblot is shown. The average band intensity of KIR2DL4 in corticosteroid-treated cells relative to that in control ethanol (EtOH)-treated cells was obtained from three independent experiments. C: The expression of MCT in LAD2 cells measured by enzyme-linked immunosorbent assay. The average MCT levels in corticosteroid-treated cells relative to those in control Et0H-treated cells were obtained from three independent experiments. ${ }^{\star \star} P<0.01$ versus EtOH. Scale bars $=20 \mu \mathrm{m}(\mathbf{A})$. GAPDH, glyceraldehyde 3-phosphate dehydrogenase.

containing $5 \times 10^{4}$ control LAD2 cells, or StemPro-34 containing $5 \times 10^{4}$ KIR2DL4-knockdown LAD2 cells were incubated in the lower chamber at $37^{\circ} \mathrm{C}$, with or without control IgG or anti-LIF neutralizing antibody (10 $\mu \mathrm{g} / \mathrm{mL})$. Then, $5 \times 10^{3}$ HTR-8/SVneo cells $(100 \mu \mathrm{L})$ were added in cytokine-free medium in the upper chamber. After an 18-hour incubation, the cells migrating to the bottom of the upper wells were fixed with $4 \%$ paraformaldehyde, stained with Diff-Quick stain (Sysmex, Kobe, Japan), and counted under a microscope.

\section{Tube Formation Assay}

Aliquots of $1500 \mu \mathrm{L}$ Corning Matrigel Basement Membrane Matrix Growth Factor Reduced (Corning, Corning, NY) were added to 6-well plates and incubated for 30 minutes at $37^{\circ} \mathrm{C}$. Then, $5 \times 10^{5}$ HTR-8/SVneo cells starved of FCS overnight were added to the presolidified Matrigel, in the presence of StemPro-34 only, StemPro-34 and $5 \times 10^{3}$ control LAD2 cells, or StemPro-34 and $5 \times 10^{3}$ KIR2DL4-knockdown LAD2 cells, in the absence or presence of control IgG or 
A

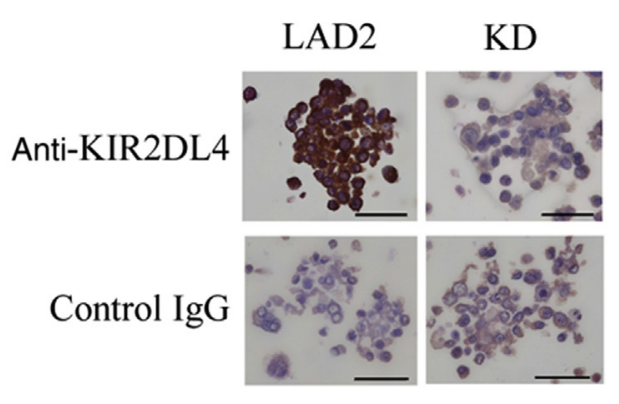

B

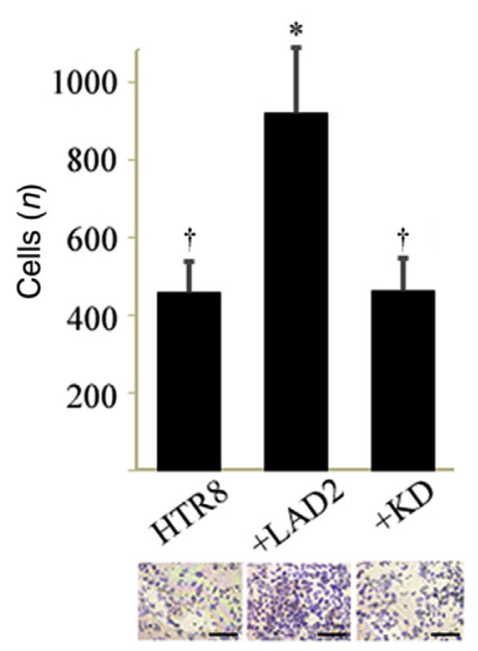

C

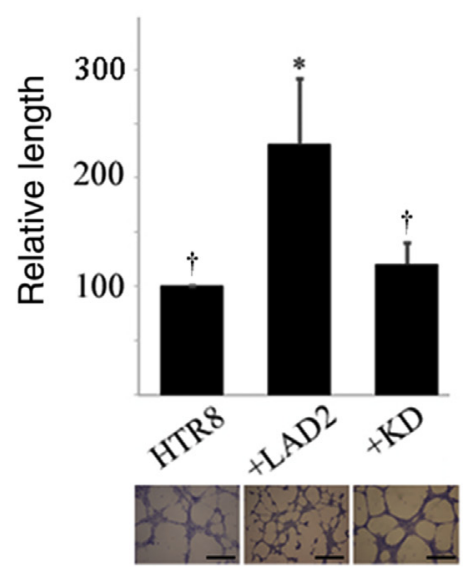

Figure 3 Co-culture with LAD2 cells induces migration and tube formation of HTR-8/SVneo in a KIR2DL4-dependent manner. A: Confirmation of KIR2DL4knockdown in LAD2 cells by immunocytochemistry. A representative image is shown. B: Migration activity. Migration was assessed using Matrigel-coated Transwell polycarbonate membranes. Aliquots of $5 \times 10^{3} \mathrm{HTR}-8 / \mathrm{SVneo}$ cells in cytokine-free medium were added to the upper chamber after preculture with medium only, $5 \times 10^{4}$ LAD2 cells infected with control vector, or $5 \times 10^{4}$ KIR2DL4-knockdown LAD2 cells were added to the bottom chamber. After an 18 hour incubation, the cells migrating to the bottom of the upper wells were counted under a microscope. The average number of cells was obtained from three independent experiments. Representative images of each group are shown. C: Tube formation activity. Aliquots of $5 \times 10^{5}$ of HTR-8/SVneo cells starved of fetal calf serum overnight were added to 6 -well plates coated with presolidified Corning Matrigel basement membrane matrix growth factor reduced. After a 10 hour incubation with or without $5 \times 10^{3}$ control LAD2 cells or $5 \times 10^{3}$ KIR2DL4-knockdown LAD2 cells in the same plates, digital images were obtained, the total length of the tubes in the field was measured, and the relative value of network formation was calculated. (The total length of HTR-8/SVneo only was given an arbitrary value of 100.) The average value was obtained from four independent experiments. Representative images of each group are shown. ${ }^{*} P<0.05$ versus HTR8; ${ }^{\dagger} P<0.05$ versus +LAD2. Scale bars: $50 \mu \mathrm{m}(\mathbf{A}) ; 100 \mu \mathrm{m}$ (B and $\left.\mathbf{C}\right) . \mathrm{KD}, \mathrm{KIR} 2 \mathrm{DL} 4$ knockdown LAD2 cells.

anti-LIF neutralizing antibody $(10 \mu \mathrm{g} / \mathrm{mL})$. After a 10 -hour incubation, digital images were obtained using a BX45 microscope (Olympus) equipped with a DP26 digital camera (Olympus). Two representative fields $(\times 200)$ were selected, the total length of the tubes in the field was measured, and the relative value of network formation was calculated (the total length of HTR-8/SVneo only was 100). ${ }^{19}$

\section{ELISA for LIF, MMP-9, and Soluble fms-Like Tyrosine Kinase 1}

LAD2 cells were cultured overnight in cytokine-free Iscove's modified Dulbecco's medium supplemented with $10 \%$ fetal bovine serum and then resuspended in StemPro34 containing human SCF.

For the assay using the anti-KIR2DL4 agonistic antibody, aliquots of $1 \times 10^{5} \mathrm{LAD} 2$ cells in $100 \mu \mathrm{L}$ of medium per well were cultured for 8 hours with control $\operatorname{IgG}$ or antiKIR2DL4 antibody ( 1 or $10 \mu \mathrm{g} / \mathrm{mL}$, respectively). For the co-culture assay, $1 \times 10^{5}$ LAD2 cells in $100 \mu \mathrm{L}$ of medium per well were cultured for 8 hours in 96-well dishes containing confluent HTR-8/SVneo cells in the presence or absence of control IgG or anti-HLA-G blocking antibody $(10 \mu \mathrm{g} / \mathrm{mL})$. Aliquots of $50 \mu \mathrm{L}$ of the supernatants were collected and used in ELISA kits [Human LIF ELISA Kit (ab100582), Human MMP9 ELISA Kit (ab100610), and Human VEGF R1 ELISA Kit (FLT1; ab119567); Abcam], according to the manufacturer's protocol.

\section{Serine Protease Activity}

Aliquots of $1 \times 10^{5}$ LAD2 cells were cultured for 8 hours with control IgG or anti-KIR2DL4 antibody ( 1 or $10 \mu \mathrm{g} / \mathrm{mL}$, respectively) or in 96-well dishes containing confluent HTR-8/SVneo cells, with or without control $\operatorname{IgG}$ or anti-HLA-G blocking antibody $(10 \mu \mathrm{g} / \mathrm{mL})$. The anti-KIR2DL4 antibody-stimulated LAD2 cells or the cocultured LAD2 and HTR-8/SVneo cells were collected, and their serine protease activity was measured using a FAM-Leu-CMK Green FLISP Assay Kit (Immunochemistry Technologies, Bloomington, MN), according to the manufacturer's protocol.

\section{RNA in Situ Hybridization}

To detect $L I F$ or $M M P 9$ mRNA-producing mast cells, RNA in situ hybridization for LIF or MMP-9 and immunostaining of MCT were performed on the same sections. First, RNA in situ hybridization was performed using RNAscope Target Probe Hs-LIF, Hs-MMP-9, or control scramble probe, and the RNAscope 2.5 HD Detection Reagent-Brown (Advanced Cell Diagnostics, Hayward, CA), according to the manufacturer's instructions, without counterstaining. The sections were incubated with anti-MCT for 30 minutes, followed by incubation with Simple Stain AP (M) (Nichirei Bioscience, Tokyo, Japan) for 30 minutes. Positive signals for MCT were visualized using a Vector Blue alkaline phosphatase substrate 
A

LIF ELISA
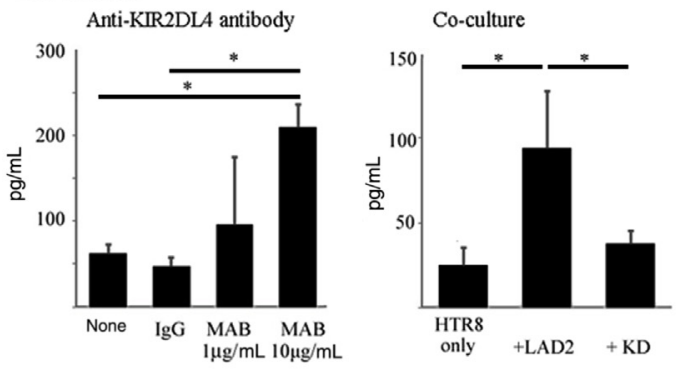

C

Immunocytochemistry (STAT3 activation in HTR-8 / SVneo cells)
B

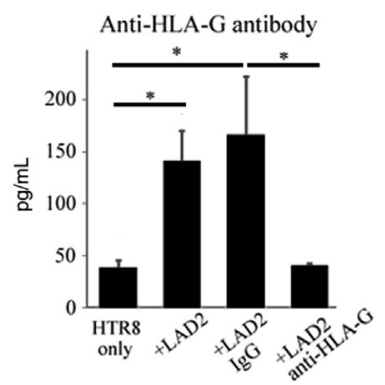

LIF mRNA in vivo

LIF mRNA (Brown) Scramble mRNA (Brown) MCT (Blue)

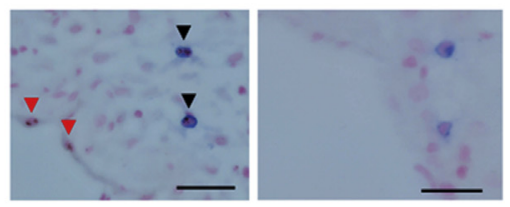

E

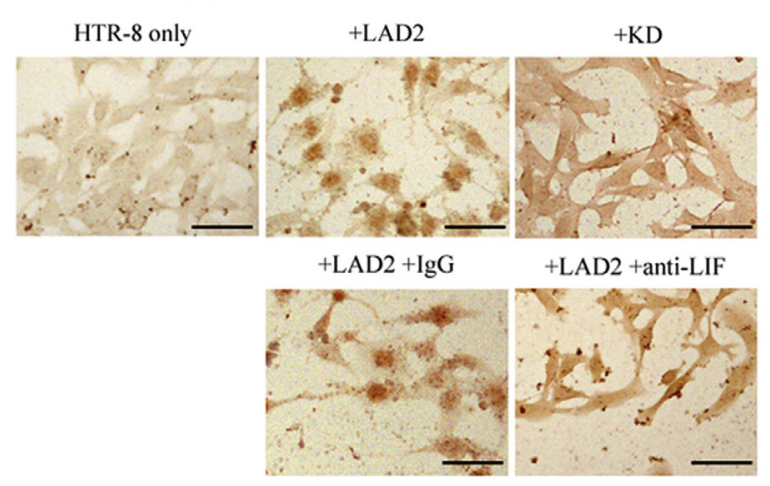

D
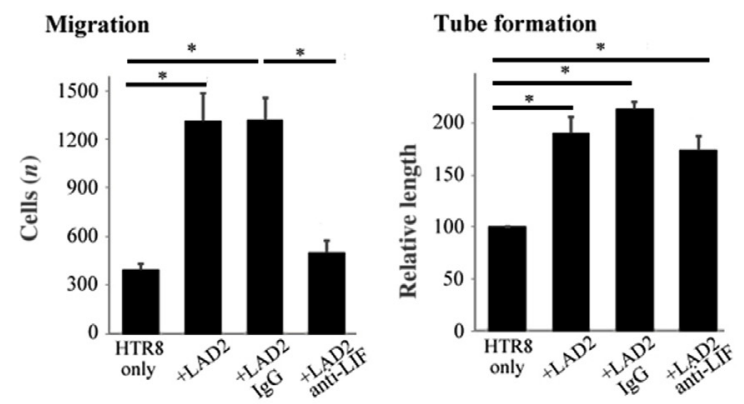

Figure 4 Leukemia inhibitory factor (LIF) is produced by LAD2 cells on KIR2DL4 stimulation and induces STAT3 activation and migration of HTR-8/SVneo cells in the co-culture system. A: LIF enzyme-linked immunosorbent assay (ELISA). LAD2 cells were incubated for 8 hours with or without control IgG $(10 \mu \mathrm{g} / \mathrm{mL})$ or anti-KIR2DL4 agonistic antibody (1 or $10 \mu \mathrm{g} / \mathrm{mL}$ ). LAD2 cells infected with control lentiviral particles or with those containing KIR2DL4-targeting shRNA were cultured in 96-well dishes containing confluent HTR-8/SVneo cells. LAD2 cells were incubated with or without control IgG $(10 \mu \mathrm{g} / \mathrm{mL})$ or anti-human leukocyte antigen-G blocking antibody $(10 \mu \mathrm{g} / \mathrm{mL})$ in 96 -well dishes containing confluent HTR-8/SVneo cells. The culture supernatants were subjected to ELISA for human LIF. Data were obtained from three independent experiments. B: LIF mRNA expression in vivo. LIF mRNA is detected by RNA scope (brown), and mast cell tryptase (MCT) protein is detected by immunohistochemistry (blue) in the decidual tissue of parous women. Black arrowheads indicate LIF mRNA-positive decidual mast cells. Red arrowheads indicate LIF mRNA-positive glandular cells. C: STAT3 activation in HTR-8/SVneo cells. Immunocytochemistry was used to detect STAT3 activation (presence of phosphorylated STAT3 protein) in HTR-8/SVneo cells co-cultured with control LAD2 cells, KIR2DL4-knockdown LAD2 cells, LAD2 cells treated with control IgG $(10 \mu \mathrm{g} / \mathrm{mL})$, or LAD2 cells treated with anti-human LIF neutralizing antibody $(10 \mu \mathrm{g} / \mathrm{mL})$. Data were obtained from three independent experiments. Representative images of each group are shown. D: Migration activity. Aliquots of $5 \times 10^{3} \mathrm{HTR}-8 / \mathrm{SVneo}$ cells in cytokine-free medium were added to the upper chamber after preculture of medium only, $5 \times 10^{4}$ LAD2 cells, $5 \times 10^{4}$ LAD2 cells with control IgG $(10 \mu \mathrm{g} / \mathrm{mL})$, or $5 \times 10^{4} \mathrm{LAD2}$ cells with anti-human LIF neutralizing antibody $(10 \mu \mathrm{g} / \mathrm{mL})$ in the bottom chamber. After an 18-hour incubation, the cells migrating to the bottom of the upper wells were counted under a microscope. Data were obtained from three independent experiments. E: Tube formation activity. Aliquots of $5 \times 10^{5}$ of HTR-8/SVneo cells starved of fetal calf serum overnight were added to 6-well plates coated with presolidified Corning Matrigel basement membrane matrix growth factor reduced. After a 10-hour incubation with or without $5 \times 10^{3}$ LAD2 cells, $5 \times 10^{3}$ LAD2 cells with control IgG $(10 \mu \mathrm{g} / \mathrm{mL})$, or $5 \times 10^{3}$ LAD2 cells with anti-human LIF neutralizing antibody $(10 \mu \mathrm{g} / \mathrm{mL})$ in the same plates, digital images were acquired. The total length of tubes in the field was measured, and the relative value of network formation was calculated. (The total length of HTR-8/SVneo only was given an arbitrary value of 100.) Data were obtained from three independent experiments. ${ }^{*} P<0.05$. Scale bars $=50 \mu \mathrm{m}$ (B and C). KD, KIR2DL4 knockdown LAD2 cells; MAB, anti-KIR2DL4 monoclonal antibody.

kit (Vector Laboratories, Burlingame, CA). Nuclei were stained with methyl green.

\section{ELISA for Protease-Activated Receptors}

LAD2 cells were cultured overnight in cytokine-free Iscove's modified Dulbecco's medium supplemented with 10\% FCS, then resuspended in StemPro-34 containing human SCF. Aliquots of $1 \times 10^{5} \mathrm{LAD} 2$ cells in $100 \mu \mathrm{L}$ of medium per well were cultured for 8 hours in 96-well dishes containing confluent HTR-8/SVneo cells, with or without dimethyl sulfoxide or GM6001 $(0.5 \mathrm{nmol} / \mathrm{L})$. After three washes with phosphate-buffered saline, all of the adherent HTR-8/SVneo cells were collected and lysed. After two washes with cytokine-free Iscove's modified Dulbecco's medium without FCS, the lysates were used for ELISA kits [Human F2/Prothrombin/Thrombin ELISA Kit (LS-F23664-1) and Human F2RL1/PAR2 ELISA Kit (LS-F5365-1); LifeSpan Biosciences, Seattle, WA], according to the manufacturer's protocol.

\section{Statistical Analysis}

Differences between groups were examined for statistical significance using the $U$-test (Microsoft Excel 2013; Microsoft Corp., Redmond, WA) or $t$-test (Microsoft Excel 
A

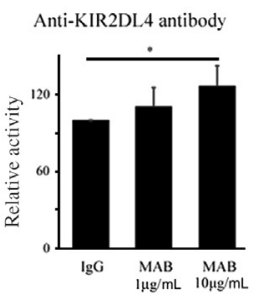

C

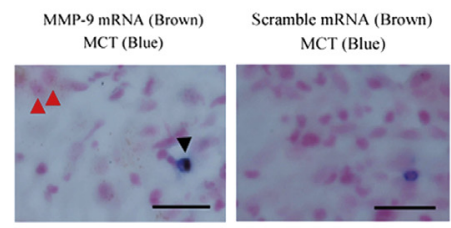

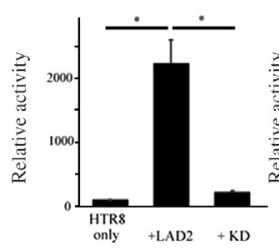

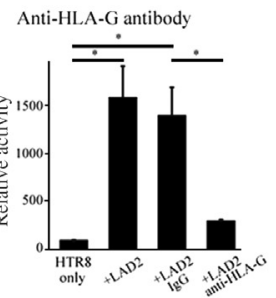

D

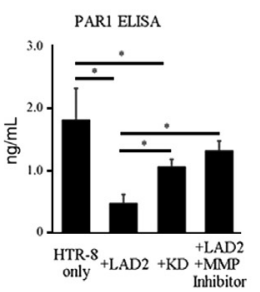

B
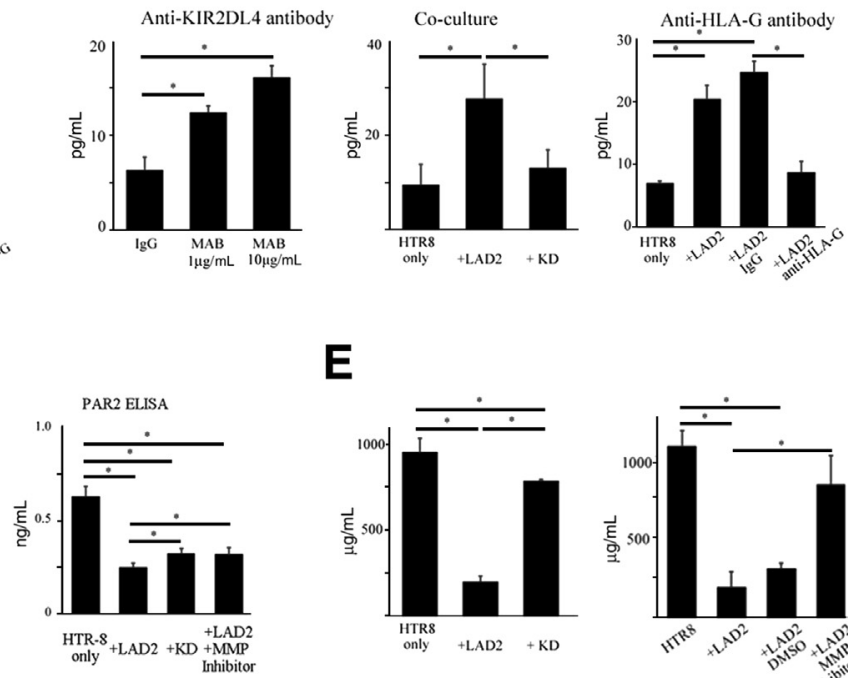

$\mathbf{E}$

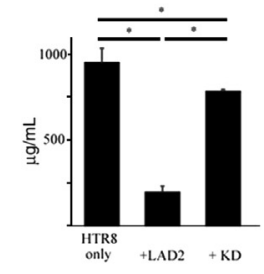

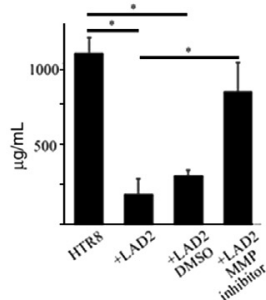

Figure 5 Serine proteases, probably including matrix metallopeptidase (MMP)-9, were produced by LAD2 cells on KIR2DL4 stimulation, degraded proteaseactivated receptors (PARs), and decreased the production of soluble fms-like tyrosine kinase 1 (sFlt-1) in HTR-8/SVneo cells in the co-culture system. A: Relative serine protease activity. Aliquots of $1 \times 10^{5}$ LAD2 cells were cultured for 8 hours with control IgG $(10 \mu \mathrm{g} / \mathrm{mL})$ or anti-KIR2DL4 antibody $(1 \mathrm{or} 10 \mu \mathrm{g} /$ $\mathrm{mL})$. A total of $1 \times 10^{5}$ LAD2 cells infected with control lentiviral particles or with those containing KIR2DL4-specific shRNA were cultured in 96-well dishes containing confluent HTR-8/SVneo cells. LAD2 cells were treated with or without control IgG $(10 \mu \mathrm{g} / \mathrm{mL})$ or anti-human leukocyte antigen (HLA)-G antibody $(10 \mu \mathrm{g} / \mathrm{mL})$ in 96 -well dishes containing confluent HTR-8/SVneo cells. The stimulated cells were collected, and their serine protease activity was measured using a FAM-Leu-CMK green FLISP assay kit. Data were obtained from three independent experiments. B: MMP-9 enzyme-linked immunosorbent assay (ELISA). LAD2 cells were incubated for 8 hours with control IgG $(10 \mu \mathrm{g} / \mathrm{mL})$ or anti-KIR2DL4 agonistic antibody (1 or $10 \mu \mathrm{g} / \mathrm{mL})$. LAD2 cells infected with control lentiviral particles or with those containing KIR2DL4-targeting shRNA were cultured in 96-well dishes containing confluent HTR-8/SVneo cells. LAD2 cells with or without control IgG $(10 \mu \mathrm{g} / \mathrm{mL})$ or anti-HLA-G antibody $(10 \mu \mathrm{g} / \mathrm{mL})$ were cultured in 96 -well dishes containing confluent HTR-8/SVneo cells. The culture supernatants were subjected to ELISA for human MMP-9. Data were obtained from three independent experiments. C: MMP9 mRNA expression in vivo. MMP9 mRNA is detected by RNA scope (brown), and mast cell tryptase (MCT) protein is detected by immunohistochemistry (blue) in the decidual tissue of parous women. Black arrowhead indicates MMP9 mRNA-positive decidual mast cells. Red arrowheads indicate MMP9 mRNA-positive stromal cells. D: PAR ELISA. LAD2 cells infected with control vector or KIR2DL4-knockdown LAD2 cells were incubated for 8 hours in 96-well dishes containing confluent HTR-8/SVneo cells with or without the MMP inhibitor, GM6001 $(0.5 \mathrm{nmol} / \mathrm{L})$. After three washes, the adherent cells were collected and subjected to ELISA for human PAR1 or PAR2. E: sFlt-1 ELISA. LAD2 cells infected with control lentiviral particle or with those containing KIR2DL4-targeting shRNA were cultured in 96-well dishes containing confluent HTR-8/SVneo cells. LAD2 cells were treated with dimethyl sulfoxide or with the MMP-9 inhibitor GM6001 for 8 hours in 96-well dishes containing confluent HTR-8/SVneo cells. The culture supernatants were subjected to ELISA for human sFlt-1. Data were obtained from three independent experiments. ${ }^{*} P<0.05$. Scale bars $=50 \mu \mathrm{m}$ (C). KD, KIR2DL4 knockdown LAD2 cells; MAB, anti-KIR2DL4 monoclonal antibody.

2013). Data are expressed as means \pm SEM. $P<0.05$ was considered statistically significant.

\section{Results}

\section{Decidual Mast Cells Decrease in Infertile Women Who Had Undergone Long-Term Corticosteroid Treatment}

First, the status of human decidual mast cells in parous women was compared with the status in infertile women, with decidual tissues derived from parous women as controls. The presence of mast cells (MCT positive) was confirmed in the decidual tissue of parous women (33.4 \pm 6.92 cells) (Figure 1A). A subpopulation of infertile women who had undergone long-term corticosteroid treatment for autoimmune diseases or after transplantation (Table 1) had significantly reduced numbers of mast cells in the decidua in the first trimester $(2.20 \pm 0.89$ cells $)$ (Figure 1A). No such decrease in the number of decidual mast cells was observed in the women with infertility of unknown cause $(23.7 \pm 3.51$ cells) (Figure $1 \mathrm{~A})$.

Tregs are thought to induce the migration of mast cells to the decidual tissue in mice. ${ }^{7}$ It was examined whether decreased numbers of decidual mast cells were associated with reduced Treg (CD3 and FOXP3 positive) numbers in infertile women who had undergone long-term corticosteroid treatment. There was no significant difference in the number of decidual Tregs among parous women, women with infertility of unknown cause, and infertile women who had undergone long-term corticosteroid treatment $(13.3 \pm 3.88$, $11.3 \pm 3.87$, and $16.3 \pm 4.23$ cells, respectively) (Figure 1B).

\section{Decidual Mast Cells Express KIR2DL4 Protein in Parous Women but Not in Infertile Women Who Had Undergone Long-Term Corticosteroid Treatment}

Recently, we reported the expression of KIR2DL4 protein in human mast cells ${ }^{9}$ and evaluated the expression of 


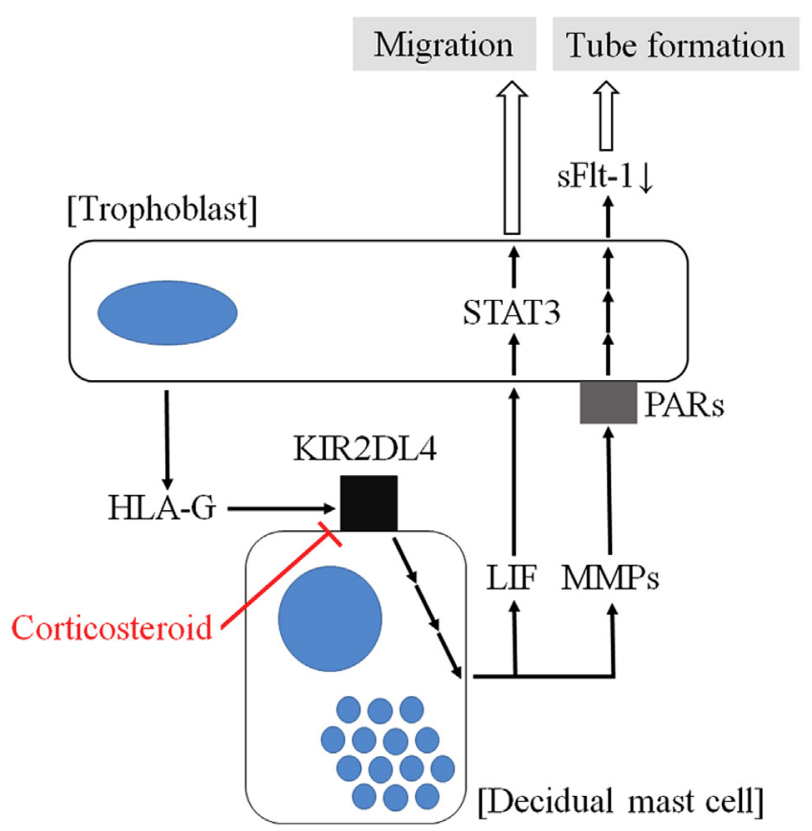

Figure 6 Proposed model. Human leukocyte antigen (HLA)-G of trophoblasts stimulates KIR2DL4 on decidual mast cells, leading to the production of leukemia inhibitory factor (LIF) and serine proteases. LIF enhances STAT3 activation and migration of trophoblasts, whereas serine proteases degrade protease-activated receptors (PARs) and induce tube formation of trophoblasts. The interaction between trophoblasts and decidual mast cells can play important roles in the establishment of pregnancy. Long-term corticosteroid suppresses the expression of KIR2DL4 on decidual mast cells. MMP, matrix metallopeptidase; sFlt, soluble fms-like tyrosine kinase.

KIR2DL4 on human decidual mast cells. Herein, immunohistochemical methods were used to evaluate the expression of KIR2DL4 in decidual mast cells. The expression of KIR2DL4 protein was confirmed in MCT-positive cells, a marker of decidual mast cells, from all parous women and infertile women who did not undergo corticosteroid treatment (Figure 2A). However, the expression of KIR2DL4 was undetectable in the decidual mast cells of infertile women who had undergone long-term corticosteroid treatment (Figure 2A). The MCT-negative and KIR2DL4positive cells were thought to be decidual NK cells. ${ }^{14}$

To explore the effect of corticosteroid on mast cells, LAD2 cells were treated with the corticosteroid, dexamethasone. KIR2DL4 protein expression and MCT contents were significantly reduced in corticosteroid-treated LAD2 cells compared with those in control (ethanol-treated) LAD2 cells (Figure 2, B and C).

Co-Culture of the Human Mast Cell Line, LAD2, and Trophoblast Cell Line, HTR-8/SVneo, Accelerates Migration and Tube Formation of HTR-8/SVneo Cells

The abnormal phenotypes of decidual mast cells were observed in a subpopulation of infertile women. KIR2DL4 is a receptor for HLA-G, which is physiologically expressed by trophoblasts, and is essential for the establishment of pregnancy. ${ }^{12}$ We hypothesized that KIR2DL4 on decidual mast cells was involved in the establishment of pregnancy by interacting with HLA-G on trophoblasts and evaluated the effects of co-culture between a human mast cell line LAD2 expressing KIR2DL4 ${ }^{9}$ and a trophoblast cell line HTR-8/ SVneo expressing soluble and membrane-bound forms of HLA-G. ${ }^{16,20,21}$ Migration and angiogenesis of trophoblasts are essential processes for the establishment of pregnancy; the effects of HTR-8/SVneo cells on these phenotypes were evaluated using the co-culture system. The migration ability of HTR-8/SVneo cells was assessed by two-chamber assay. Herein, the KIR2DL4-knockdown LAD2 cells established previously $^{9}$ and the off-target shRNA-treated LAD2 cells were used as control LAD2 cells (Figure 3A). KIR2DL4 silencing suppresses the proliferation and degranulation of LAD2 cells and enhances the secretion of a serine protease granzyme B via Src homology region 2 domain-containing phosphatase (SHP)-2 activation. ${ }^{9}$ Co-culture with control LAD2 cells accelerated the migration of HTR-8/SVneo cells compared with single culture of HTR-8/SVneo (Figure 3B). However, co-culture with KIR2DL4-knockdown LAD2 cells did not accelerate these processes (Figure 3B). The angiogenesis ability of HTR-8/SVneo cells was assessed by tube formation assay. Similar to the observations regarding migration ability, co-culture with control LAD2 cells accelerated the tube formation of HTR-8/SVneo cells in comparison to the single culture of HTR-8/SVneo, but co-culture with KIR2DL4-knockdown LAD2 cells showed no such effect (Figure 3C). Thus, LAD2 accelerated the migration and tube formation of HTR-8/SVneo in a KIR2DL4-dependent manner.

LIF Is Produced by LAD2 Cells by KIR2DL4 Stimulation and Induces STAT3 Activation in HTR-8/SVneo Cells in the Co-Culture System

LIF is known to control the biology of trophoblasts. ${ }^{22}$ LIF production of LAD2 cells was evaluated on KIR2DL4 stimulation. LIF production by LAD2 cells was induced when stimulated with anti-KIR2DL4 agonistic antibody or when co-cultured with HTR-8/SVneo cells (Figure 4A). LIF production was also evaluated in control LAD2 and KIR2DL4-knockdown LAD2 cells when co-cultured with HTR-8/SVneo cells. The level of LIF production in KIR2DL4-knockdown LAD2 cells was significantly lower than that of control LAD2 cells when co-cultured with HTR-8/SVneo cells (Figure 4A). In addition, treatment with anti-HLA-G neutralizing antibody significantly inhibited LIF production in LAD2 cells co-cultured with HTR-8/ SVneo cells (Figure 4A). Therefore, LAD2 produced LIF on KIR2DL4 stimulation. Next, the expression of LIF mRNA was examined in decidual mast cells from the pathological specimens. The RNA scope assay revealed the expression of LIF mRNA in decidual mast cells and in most glandular cells and some stromal cells ${ }^{23}$ of parous women (Figure 4B). 
LIF activates STAT3 in trophoblasts, and this is followed by enhancement of their migration activity. ${ }^{24}$ Immunocytochemical examination of the STAT3 status of HTR-8/ SVneo cells when co-cultured with LAD2 cells was performed. Co-culture with LAD2 cells induced nuclear localization of STAT3, comparable to STAT3 activation, in HTR-8/SVneo cells (Figure 4C). STAT3 activation was abrogated by administration of anti-human LIF neutralizing antibody $(10 \mu \mathrm{g} / \mathrm{mL})$ in the co-culture system (Figure $4 \mathrm{C})$. No activation of STAT3 was detected in the co-culture of KIR2DL4-knockdown LAD2 cells and HTR-8/SVneo cells (Figure 4C). Thus, LIF was produced by LAD2 cells on KIR2DL4 stimulation and induced STAT3 activation in HTR-8/SVneo cells in the co-culture system.

Next, the effects of LAD2-secreted LIF were examined on migration and tube formation of HTR-8/SVneo cells. Migration was abrogated by administration of anti-human LIF neutralizing antibody $(10 \mu \mathrm{g} / \mathrm{mL})$ in the co-culture system (Figure 4D), but tube formation was not significantly affected (Figure 4E).

\section{MMP-9 Is Produced by LAD2 Cells on KIR2DL4}

Stimulation, Degraded PARs, and Down-Regulated Production of sFlt-1 by HTR-8/SVneo Cells in the Co-Culture System

Serine proteases are also known to control the migration and tube formation of trophoblasts. ${ }^{22}$ The serine protease activity of LAD2 cells on KIR2DL4 stimulation was evaluated. Administration of the anti-KIR2DL4 agonistic antibody significantly increased the serine protease activity of LAD2 cells (Figure 5A). Although co-culture of control LAD2 cells with HTR-8/SVneo cells showed markedly increased serine protease activity, co-culture of KIR2DL4knockdown LAD2 cells with HTR-8/SVneo cells had no such effect (Figure 5A). Moreover, treatment with anti-HLA-G neutralizing antibody led to decreased serine protease activity in LAD2 cells when co-cultured with HTR-8/SVneo cells (Figure 5A). MMP-9 is a serine protease that plays key roles in trophoblast biology. ${ }^{22}$ Administration of anti-KIR2DL4 agonistic antibody increased MMP-9 production by LAD2 cells (Figure 5B). The level of MMP-9 production in KIR2DL4-knockdown LAD2 cells was significantly lower than that in control LAD2 cells when co-cultured with HTR-8/SVneo cells (Figure 5B). In addition, treatment of anti-HLA-G neutralizing antibody decreased the MMP-9 serine protease activity in LAD2 cells co-cultured with HTR-8 cells (Figure 5B). MMP-2 production was not detected in LAD2 cells (data not shown). Therefore, LAD2 produced MMP-9 on KIR2DL4 stimulation.

Next, the expression of MMP9 mRNA was examined in decidual mast cells in the pathologic specimens. The RNA scope assay revealed the expression of MMP9 mRNA in decidual mast cells and in some stromal cells ${ }^{25}$ of parous women (Figure 5C).
Serine proteases induce the degradation of proteaseactivated receptors (PARs) on trophoblasts and reduce the secretion of soluble fms-like tyrosine kinase 1 (sFlt-1), an inhibitor of trophoblast angiogenesis. ${ }^{26,27}$ Next, the status of PARs and sFlt-1 secretion was evaluated in the co-culture system. Co-culture decreased the PAR protein levels of HTR-8/SVneo cells (Figure 5D), probably by degradation, and reduced the level of sFlt-1 production (Figure $5 \mathrm{E}$ ). The degrees of the reductions in PAR and sFlt-1 levels in coculture with KIR2DL4-knockdown LAD2 cells were smaller to those in co-culture with control LAD2 cells (Figure 5, D and E). The MMP inhibitor, GM6001, partially abrogated the reduction observed in PAR protein levels (Figure 5D) and sFlt-1 secretion (Figure 5E), suggesting that MMPs were partially involved in this process. In summary, serine proteases, probably including MMP-9, were produced by LAD2 cells on KIR2DL4 stimulation, which degraded PARs and decreased the production of sFlt-1 by HTR-8/SVneo cells in the co-culture system.

\section{Discussion}

The results of the present study indicated that human mast cells can enhance the biological behaviors of trophoblasts to establish pregnancy via KIR2DL4 (Figure 6). In addition, corticosteroid treatment of human mast cells suppressed this process, and may result in infertility.

Woidacki and colleagues $^{6-8}$ reported the possible involvement of mast cells in this process. They showed that mast cell deficiency in the murine uterus reduced the possibility of establishing pregnancy, and mast cell transfer to the uterus abolished this effect. ${ }^{6}$ This was compatible with the observation of markedly decreased decidual mast cell number associated with the infertility in the corticosteroidtreated women in the present study. We expect that some cases of infertility associated with corticosteroid treatment may be resolved by supplementation of human mast cells into the uterus, as observed in experiments using mast cell-deficient $K I T^{W-s h / W-s h}$ mice. ${ }^{6}$

The data suggest that decidual mast cells contribute to pregnancy via the production of LIF and serine proteases, such as MMP-9, which likely enhance angiogenesis (tube formation) of trophoblasts by decreasing the secretion of antiangiogenesis factor sFlt-1. Levels of sFlt- 1 in decidual tissues might be predictive of infertility associated with mast cell abnormality, in addition to its role as a marker for preeclampsia. $^{28}$ The KIR2DL4-stimulated secretion of another serine protease, granzyme B, is mediated by SHP-2 in human mast cells. ${ }^{9}$ Herein, it was also observed that SHP-2 inhibitor partially suppressed the secretion of LIF and MMP-9 from LAD2 cells (data not shown). KIR2DL4 stimulation and SHP-2 activation in human decidual mast cells can potentially improve fertility status by up-regulating LIF and serine protease secretion. Consistent with what was previously reported, ${ }^{20,21}$ data obtained from the two-chamber assay 
suggest that the administration of soluble HLA-G protein may be used to stimulate KIR2DL4 on decidual mast cells.

The results presented herein indicated the importance of KIR2DL4 in the establishment of pregnancy. KIR2DL4 is a human-specific gene ${ }^{11}$ and would be associated with differences in the mechanisms of pregnancy between humans and other species. ${ }^{29}$ In mice, mast cell chymase reportedly enhanced the angiogenesis of decidual tissues, ${ }^{8}$ although our results showed that human mast cell chymase expression was down-regulated by KIR2DL4 stimulation (data not shown). Mast cell chymase may be associated with the establishment of pregnancy in a KIR2DL4-independent manner or may not be associated with the establishment of pregnancy in humans.

Transfer of Tregs into the decidual tissue increased the number of decidual mast cells in mice. ${ }^{7}$ However, by comparing samples obtained from parous women with those from corticosteroid-treated women, this study indicated that Treg number did not significantly correlate with decidual mast cell number. IL-9 produced by Treg induces the migration of mast cells. ${ }^{30}$ However, no difference was found in IL9 mRNA expression in Treg or IL-9 receptor protein expression in decidual mast cells among the parous women, women with infertility of unknown cause, and infertile women who had undergone long-term corticosteroid treatment (data not shown).

Like decidual Tregs, decidual NK cells also play important roles in pregnancy. ${ }^{31}$ In mice, both decidual NK cells and mast cells enhanced angiogenesis by producing chymase. ${ }^{8}$ In humans, some women with recurrent spontaneous abortion showed decreased protein expression of KIR2DL4 in NK cells, ${ }^{14}$ although it remains unclear whether KIR2DL4 expression of decidual mast cells was also affected in these subjects. In this study, the KIR2DL4 expression of decidual mast cells was significantly lower in the corticosteroid-administrated infertile patients. In addition, it was found that KIR2DL4 expression of decidual NK cells was maintained by long-term treatment of corticosteroid (data not shown), even when that of the decidual mast cells fell below detection limit. These observations suggest the existence of a distinct regulatory mechanism of KIR2DL4 expression in NK cells and mast cells during pregnancy. The association and interaction among mast cells, NK cells, and Tregs in the decidual tissues during pregnancy warrant further studies.

Corticosteroids are effective for the treatment of allergic reactions, partially by suppressing mast cell function. For example, corticosteroid was shown to suppress MCT production and SCF-induced migration of mast cells of human, rat, and other origins. ${ }^{32-35}$ The SCF-induced migration may be associated with depletion of long-term corticosteroid treatment in decidual mast cells. Corticosteroids have also been used in infertility treatment. ${ }^{36}$ However, the advantages and disadvantages of this therapy have been a matter of some debate. ${ }^{37}$ The results of the present study seem to support the disadvantages of this therapy in relation to suppression of human mast cell function. Examination of mast cell status, numbers, and/or KIR2DL4 expression in curettage samples may provide more insights into the improvement of infertility treatment.

\section{Acknowledgments}

We thank Dr. Arnold S. Kirshenbaum for the LAD2 cells and Dr. Charles H. Graham for the HTR-8/SVneo cells.

T.R.K. and H.H. designed the study; T.R.K. and T.N. designed the experiments; T.R.K., T.N., and H.H. wrote the manuscript; C.U., T.R.K., M.H., and A.S. performed in vitro experiments; T.R.K., Y.I., and S.M. analyzed clinical and pathological data.

\section{Supplemental Data}

Supplemental material for this article can be found at https://doi.org/10.1016/j.ajpath.2018.02.012.

\section{References}

1. Arck PC, Hecher K: Fetomaternal immune cross-talk and its consequences for maternal and offspring's health. Nat Med 2013, 19: $548-556$

2. Figueiredo AS, Schumacher A: The T helper type 17/regulatory T cell paradigm in pregnancy. Immunology 2016, 148:13-21

3. Gilfillan AM, Austin SJ, Metcalfe DD: Mast cell biology: introduction and overview. Adv Exp Med Biol 2011, 716:2-12

4. Horie K, Fujita J, Takakura K, Kanzaki H, Suginami H, Iwai M, Nakayama H, Mori T: The expression of c-kit protein in human adult and fetal tissues. Hum Reprod 1993, 8:1955-1962

5. Menzies FM, Higgins CA, Shepherd MC, Nibbs RJ, Nelson SM: Mast cells reside in myometrium and cervix, but are dispensable in mice for successful pregnancy and labor. Immunol Cell Biol 2012, 90:321-329

6. Woidacki K, Popovic M, Metz M, Schumacher A, Linzke N, Teles A, Poirier F, Fest S, Jensen F, Rabinovich GA, Maurer M, Zenclussen AC: Mast cells rescue implantation defects caused by c-kit deficiency. Cell Death Dis 2013, 4:e462

7. Woidacki K, Meyer N, Schumacher A, Goldschmidt A, Maurer M, Zenclussen AC: Transfer of regulatory T cells into abortion-prone mice promotes the expansion of uterine mast cells and normalizes early pregnancy angiogenesis. Sci Rep 2015, 5:13938

8. Meyer N, Woidacki K, Knöfler M, Meinhardt G, Nowak D, Velicky P, Pollheimer J, Zenclussen AC: Chymase-producing cells of the innate immune system are required for decidual vascular remodeling and fetal growth. Sci Rep 2017, 7:45106

9. Ueshima C, Kataoka TR, Hirata M, Furuhata A, Suzuki E, Toi M, Tsuruyama T, Okayama Y, Haga H: The killer cell Ig-like receptor 2DL4 expression in human mast cells and its potential role in breast cancer invasion. Cancer Immunol Res 2015, 3:871-880

10. Rajalingam R: Overview of the killer cell immunoglobulin-like receptor system. Methods Mol Biol 2012, 882:391-414

11. Faure M, Long EO: KIR2DL4 (CD158d), an NK cell-activating receptor with inhibitory potential. J Immunol 2002, 168:6208-6214

12. Rajagopalan S, Long EO: KIR2DL4 (CD158d): an activation receptor for HLA-G. Front Immunol 2012, 3:258

13. Kovats S, Main EK, Librach C, Stubblebine M, Fisher SJ, DeMars R A class I antigen, HLA-G, expressed in human trophoblasts. Science 1990, 248:220-223 
14. Yan WH, Lin A, Chen BG, Zhou MY, Dai MZ, Chen XJ, Gan LH, Zhu M, Shi WW, Li BL: Possible roles of KIR2DL4 expression on uNK cells in human pregnancy. Am J Reprod Immunol 2007, 57:233-242

15. Kirshenbaum AS, Akin C, Wu Y, Rottem M, Goff JP, Beaven MA, Rao VK, Metcalfe DD: Characterization of novel stem cell factor responsive human mast cell lines LAD 1 and 2 established from a patient with mast cell sarcoma/leukemia: activation following aggregation of FceRI or Fc $\gamma$ RI. Leuk Res 2003, 27:677-682

16. Graham CH, Hawley TS, Hawley RG, MacDougall JR, Kerbel RS, Khoo N, Lala PK: Establishment and characterization of first trimester human trophoblast cells with extended lifespan. Exp Cell Res 1993, 206:204-211

17. Da Silva CA, Kassel O, Mathieu E, Massard G, Gasser B, Frossard N: Inhibition by glucocorticoids of the interleukin-1beta-enhanced expression of the mast cell growth factor SCF. Br J Pharmacol 2002, 135:1634-1640

18. Kataoka TR, Kumanogoh A, Bandara G, Metcalfe DD, Gilfillan AM: CD72 negatively regulates KIT-mediated responses in human mast cells. J Immunol 2010, 184:2468-2475

19. Li P, Guo W, Du L, Zhao J, Wang Y, Liu L, Hu Y, Hou Y: microRNA-29b contributes to pre-eclampsia through its effects on apoptosis, invasion and angiogenesis of trophoblast cells. Clin Sci (Lond) 2013, $124: 27-40$

20. Guo W, Fang L, Li B, Xiao X, Chen S, Wang J, Yang F, Chen L, Wang X: Decreased human leukocyte antigen-G expression by miR133a contributes to impairment of proinvasion and proangiogenesis functions of decidual NK cells. Front Immunol 2017, 8:741

21. Klitkou L, Dahl M, Hviid TV, Djurisic S, Piosik ZM, Skovbo P, Møller AM, Steffensen R, Christiansen OB: Human leukocyte antigen (HLA)-G during pregnancy part I: correlations between maternal soluble HLA-G at midterm, at term, and umbilical cord blood soluble HLA-G at term. Hum Immunol 2015, 76:254-259

22. Staun-Ram E, Shalev E: Human trophoblast function during the implantation process. Reprod Biol Endocrinol 2005, 3:56

23. Chen HF, Chao KH, Shew JY, Yang YS, Ho HN: Expression of leukemia inhibitory factor and its receptor is not altered in the decidua and chorionic villi of human anembryonic pregnancy. Hum Reprod 2004, 19:1647-1654

24. Poehlmann TG, Fitzgerald JS, Meissner A, Wengenmayer T, Schleussner E, Friedrich K, Markert UR: Trophoblast invasion: tuning through LIF, signalling via Stat3. Placenta 2005, 26 Suppl A:S37-S41

25. Seval Y, Akkoyunlu G, Demir R, Asar M: Distribution patterns of matrix metalloproteinase (MMP)-2 and -9 and their inhibitors (TIMP-1 and TIMP-2) in the human decidua during early pregnancy. Acta Histochem 2004, 106:353-362

26. Zhao $Y$, Koga $K$, Osuga $Y$, Nagai M, Izumi G, Takamura M, Harada M, Hirota Y, Yoshino O, Taketani Y: Thrombin enhances soluble Fms-like tyrosine kinase 1 expression in trophoblasts: possible involvement in the pathogenesis of preeclampsia. Fertil Steril 2012, 98: 917-921

27. Huang QT, Chen JH, Hang LL, Liu SS, Zhong M: Activation of PAR1/NADPH oxidase/ROS signaling pathways is crucial for the thrombin-induced sFlt-1 production in extravillous trophoblasts: possible involvement in the pathogenesis of preeclampsia. Cell Physiol Biochem 2015, 35:1654-1662

28. Allen RE, Rogozinska E, Cleverly K, Aquilina J, Thangaratinam S: Abnormal blood biomarkers in early pregnancy are associated with preeclampsia: a meta-analysis. Eur J Obstet Gynecol Reprod Biol 2014, 182:194-201

29. Clark DA: The use and misuse of animal analog models of human pregnancy disorders. J Reprod Immunol 2014, 103:1-8

30. Eller K, Wolf D, Huber JM, Metz M, Mayer G, McKenzie AN, Maurer M, Rosenkranz AR, Wolf AM: IL-9 production by regulatory $\mathrm{T}$ cells recruits mast cells that are essential for regulatory $\mathrm{T}$ cellinduced immune suppression. J Immunol 2011, 186:83-91

31. Woidacki K, Jensen F, Zenclussen AC: Mast cells as novel mediators of reproductive processes. Front Immunol 2013, 4:29

32. Smith SJ, Piliponsky AM, Rosenhead F, Elchalal U, Nagler A, LeviSchaffer F: Dexamethasone inhibits maturation, cytokine production and FceRI expression of human cord blood-derived mast cells. Clin Exp Allergy 2002, 32:906-913

33. Jeong HJ, Na HJ, Hong SH, Kim HM: Inhibition of the stem cell factor-induced migration of mast cells by dexamethasone. Endocrinology 2003, 144:4080-4086

34. Saunders PR, Marshall JS: Dexamethasone induces a down regulation of rat mast cell protease II content in rat basophilic leukaemia cells Agents Actions 1992, 36:4-10

35. King SJ, Miller HR, Newlands GF, Woodbury RG: Depletion of mucosal mast cell protease by corticosteroids: effect on intestinal anaphylaxis in the rat. Proc Natl Acad Sci U S A 1985, 82:1214-1218

36. Mamas L, Mamas E: Dehydroepiandrosterone supplementation in assisted reproduction: rationale and results. Curr Opin Obstet Gynecol 2009, 21:306-308

37. Robertson SA, Jin M, Yu D, Moldenhauer LM, Davies MJ, Hull ML, Norman RJ: Corticosteroid therapy in assisted reproduction: immune suppression is a faulty premise. Hum Reprod 2016, 31:2164-2173 